\title{
A ATRIBUIČ̃̃O/REIVINDICAÇÃO DO PAPEL ŞOCIAL NA CONSTRUÇÃO DA DEFESA DO PONTO DE VISTA
}

\section{THEATTRIBUTION/CLAIM OF THE SOCIAL ROLE IN THE CONSTRUCTION OF DEFENSE FROM THE POINT OF VIEW}

Roberta Fernandes PACHECO ${ }^{1}$

Resumo: Baseado nos estudos interacionais sobre papel (WEIZMAN, 2006, 2008; SARANGI, 2010, 2011; PACHECO, 2018a, 2018b), este trabalho objetiva analisar como a atribuição e a reivindicação do papel social são negociadas pelos interagentes na construção da defesa de seus pontos de vista na interação. O corpus é composto por quatro edições do programa Roda Viva. A partir de uma abordagem qualitativa e interpretativa, os resultados evidenciam que, ao legitimar ou refutar os papéis sociais atribuídos, assim como reivindicálos, os participantes negociam seus pontos de vista na disputa pelos melhores argumentos de convencimento da opinião pública.

Palavras-chave: Papel social. Ponto de vista. Interação. Disputa.
Abstract: Based on interactional studies on role (WEIZMAN, 2006, 2008; SARANGI, 2010, 2011; PACHECO, 2018a, 2018b), this paper aims to analyze how the attribution and claim of the social role are negotiated by the interacting agents in the construction of the defense of their points of view in the interaction. The corpus consists of four editions of Roda Viva TV show. From a qualitative and interpretative approach, the results show that, by legitimizing or refuting the assigned social roles, as well as claiming them, the participants negotiate their points of view in the dispute for the best arguments to convince public opinion.

Keywords: Social role. Point of view. Interaction. Dispute.

1 Pacheco. UFJF. E-mail: robertafepacheco@gmail.com. ORCID: http://orcid.org/0000-0001-6247-7072 
- | A atribuição/reivindicação do papel social na construção da defesa do ponto de vista

\section{Introdução}

Este artigo busca analisar como a atribuição e a reivindicação do papel social são negociadas pelos interagentes na construção da defesa de seus pontos de vista em uma entrevista-debate em contexto político. O termo entrevista-debate remete às teorizações de Emmertsen (2007) e Pacheco (2019) na definição da atividade híbrida, em que dois tipos de padrões interacionais atuam concomitantemente no discurso: o padrão pergunta e resposta - entrevista - e o padrão defesa e disputa de pontos de vista - debate.

A perspectiva interacional abarca os dois construtos teóricos que norteiam esse trabalho: o conceito de papel social e a argumentação. Consideramos Weizman (2006, 2008) e Sarangi $(2010,2011)$ na conceptualização do papel social como uma categorização de grupo e de natureza relacional, assim como na releitura de Pacheco (2018b, p. 79) em que papel é "um construto social, discursivo e inerente à atividade", sendo tornado relevante pelos interagentes no curso de suas interações.

Seguimos os modelos de Schiffrin (1987) e Gryner (2000) no que tange à argumentação. Para Schifrrin, a argumentação apresenta três componentes: posição, disputa e sustentação. Para Gryner, a sustentação ainda pode ser dividida em dois: evidência formal e evidência empírica.

O corpus é composto por quatro edições do programa Roda Viva, que se apresenta como um programa de entrevistas, em que diversos temas são abordados e discutidos pelos participantes que compõem a mesa em cada uma de suas edições.

\section{O papel social}

Ao analisar as entrevistas de notícias em contexto israelense, Weizman (2006, 2008) aborda o conceito de papel social como pressupondo uma categorização de membro de grupo, na qual um indivíduo desempenha um papel por considerar-se como "um membro de uma determinada categoria, e consequentemente assume as obrigações acarretadas por esta categoria" (WEIZMAN, 2006, p. 156). Nessa perspectiva, papel se refere ao status social que o participante possui em seu meio social, como, por exemplo, médico, professor, pai ou marido. Esse papel é dependente das relações interpessoais e dos grupos formados por essas relações, isto é, em cada categoria de grupo - seja relacionada a crenças, valores, etnias ou ocupações - há papéis definidos socialmente e cabe ao indivíduo a percepção do papel que deve ser desempenhado em uma dada situação. É a partir da percepção da situação em que se encontra que o interagente torna relevantes alguns papéis em detrimento de outros. 
Weizman defende que essa categorização de papéis perpassa os direitos e as obrigações do falante, além de envolver as expectativas interacionais do encontro. $\mathrm{Na}$ entrevista, por exemplo, os papéis sociais do entrevistado giram em torno de sua ocupação profissional/institucional, mas também podem abarcar outras categorizações sociais. De forma semelhante, o entrevistador pode manifestar mais de um papel social na entrevista, e nem sempre relativo à sua profissão, como é o caso do exemplo a seguir, destacado pela autora:

Três dias antes das eleições, após a aparição, na imprensa, de ataques ao Primeiro Ministro Benjamin Netanyahu, que culpou a imprensa por discriminálo, o jornalista Ammon Dankner faz uma distinção entre as implicações decorrentes de papéis opostos: "cidadão" versus "jornalista":

Senhor Primeiro Ministro [...] como cidadão, eu tenho uma opinião sobre o resultado das eleições na segunda-feira à noite e eu não escondo isso, mas eu devo dizer que, como jornalista, meu interesse profissional é de fato que o senhor ganhe as eleições.

(Ammon Dankner, anil o mefaxed [“I am not afraid”], Ma'ariv, 14/05/1999, p. 2). (WEIZMAN, 2006, p. 160, grifo e tradução nossos²)

Além de jornalista, que seria o papel social esperado nessa interação, atendendo à expectativa do encontro, Ammon Dankner, na entrevista citada acima, torna relevante seu papel de cidadão, perpassado pelo papel de eleitor, em oposição direta ao papel social de jornalista, marcando, através dessa oposição, seu ponto de vista em relação às eleições ocorridas naquele país.

$\mathrm{Na}$ mesma linha interacional de Weizman, Sarangi (2010, 2011), ao analisar os cenários profissionais de consultas terapêuticas, estabelece que o papel social é manifestado através das "relações sociais entre os participantes (mãe-filho, professoraluno, etc.)" (SARANGI, 2011, p. 8) e que tais relações podem fazer com que um indivíduo desempenhe diversos papéis sociais no curso de uma interação, o que é teorizado por Sarangi (2011) de Hibridismo de papel.

\footnotetext{
2 No original: "Three days before the elections for the 15th Knesset, following the outgoing Prime Minister Benjamin Netanyahu's attacks on the media, which he blamed for discriminating against him, the journalist Amnon Dankner makes a distinction between the opposing roleimplications entailed by "doing citizenship" vs. "doing professional journalism": Mr. Prime Minister [...] As a citizen, I have an opinion about what the results should be on Monday night [the elections] and I do not hide it, but I must tell you that as a journalist, my professional interest is actually that you win the elections. (Amnon Dankner, ani lo mefaxed ["I am not afraid"], Ma'ariv, May 14, 1999, p. 2).".
} 
- A atribuição/reivindicação do papel social na construção da defesa do ponto de vista

Segundo o autor, o hibridismo de papel traz consigo a possibilidade de tensão e conflito em potencial, uma vez que "um profissional poderia exercer diversos e conflitantes papéis em um encontro" (SARANGI, 2011, p. 11). Pacheco também menciona a tensão que circunda o conceito, pontuando que os diversos papéis manifestados podem ser fonte de conflito na atividade, conforme exemplo a seguir:

A entrevistadora Marília Gabriela, por exemplo, na entrevista com o ex-Ministro José Dirceu se posiciona frequentemente como (i) jornalista - da cobertura dos fatos políticos, como o mensalão, a eleição -, (ii) mulher - aproximação com a primeira mulher eleita no Brasil - e (iii) eleitora. Esses três papéis estão presentes e podem se tornar relevantes no posicionamento da jornalista em relação aos fatos discutidos na entrevista: o papel de eleitora, por exemplo, pode se tornar crucial (principalmente se for eleitora de oposição) no direcionamento das perguntas feitas ao ex-Ministro, que foi um dos dirigentes do Partido dos Trabalhadores, partido este da presidente eleita. (PACHECO, 2018a, p. 9).

Dessa forma, parte-se aqui do pressuposto de que os papéis sociais do indivíduo manifestados no encontro podem tornar-se fontes de conflito em situações de disputa por pontos de vista na interação. Como no exemplo acima, alguns papéis da entrevistadora podem entrar em disputa nos direcionamentos das perguntas e questionamentos durante a entrevista.

Ao reivindicar um determinado papel ou refutar/legitimar um papel social atribuído, o interagente se posiciona/é posicionado nesse papel, o que pode levar a novas posições e novos papéis a serem refutados ou não. Cabe ressaltar que, ao falar de posição, nos referimos aos conceitos abordados pela Teoria do Posicionamento ${ }^{3}$ (LANGENHOVE; HARRÉ, 1999), em que o indivíduo usa de posicionamentos para lidar com a situação em que se encontra, localizando-o em posições, em um sentido metafórico do termo.

A relação entre posição e discurso é bidirecional: as pessoas são posicionadas através das práticas discursivas, isto é, uma posição é criada dentro da fala e através dela, pois possui uma natureza relacional, ou seja, "se A se posiciona como poderoso em relação à $B$, então $B$ é posicionado como menos poderoso em relação à $A$, e vice versa" (LANGENHOVE; HARRÉ, 1999, p. 1-2). As posições, então, indicam a forma como cada pessoa concebe a si mesmo e aos outros; são efêmeras e podem ser disputadas e também se tornar tema da disputa.

3 A Teoria do Posicionamento surgiu como uma alternativa à concepção estática da noção de papel na visão dramatúrgica de Goffman (2005 [1959]), atribuindo à posição um conceito mais dinâmico e interacional. Os autores definem o posicionamento como um processo discursivo pelo qual as pessoas são localizadas nas conversas como participantes coerentes em linhas de história - storylines - que são construídas conjuntamente. 


\section{O ponto de vista}

Defender pontos de vista é o princípio básico da argumentação, uma vez que, em uma perspectiva interacional (SCHIFFRIN, 1987), a argumentação é coconstruída na interação, em um processo dialógico em que um argumento é "construído entre alguém que apresenta um ponto de vista e alguém que o desafia" (VAN EEMEREN et al., 1997, p. 208). Van Eemeren et al. (1997, p. 209, tradução nossa ${ }^{4}$ ) apresentam duas características centrais para o conceito de argumentação:

1) Proposições apresentadas como asserções e outras proposições apresentadas como justificação e/ou refutação daquelas asserções;

2) Os argumentos dizem respeito a uma questão que tem dois lados e provêm de dois conversacionalistas: um protagonista que apresenta uma asserção e um antagonista que questiona esta asserção, a contradiz ou nega assentimento a ela.

Sendo assim, o objetivo do falante na argumentação consiste em justificar ou refutar um ponto de vista, com a meta de convencer o interlocutor da aceitabilidade ou inaceitabilidade de uma postura frente a esse ponto de vista. Assim, há uma ideia e um compromisso assumido a respeito da posição defendida (VIEIRA, 2002).

Schiffrin (1987, p. 18) já havia estabelecido que a ideia, o compromisso e ainda a representação são elementos do componente posição, que junto com o componente disputa e a sustentação formam as "três partes do argumento". A ideia é a parte central da posição retratando as informações descritivas de situações, estados, eventos e ações no mundo; o compromisso é demonstrado através de uma asserção, ou seja, a reivindicação da verdade de uma proposição; a representação é considerada a forma adotada pelo falante para apresentar a ideia, podendo aumentar o volume da voz, manter o piso conversacional por um longo período, ou ainda parecer que fala para uma plateia maior do que a que está na presença imediata dele.

Nos termos de Schiffrin, a defesa da posição assumida pelo interagente se realiza através da sustentação, que seriam seus argumentos de defesa. Ao contestar essa posição, o outro interagente apresenta sua contraposição, iniciando a disputa no processo argumentativo interacional. Podemos esquematizar a proposta de Schiffrin da seguinte forma:

4 No original: "1) propositions presented as assertions and other propositions presented as justification and / or refutation of those assertions;

2) The arguments concern an issue that has two sides and comes from two conversationalists: a protagonist who presents an assertion and an antagonist, who questions this assertion, contradicts it or denies it.". 


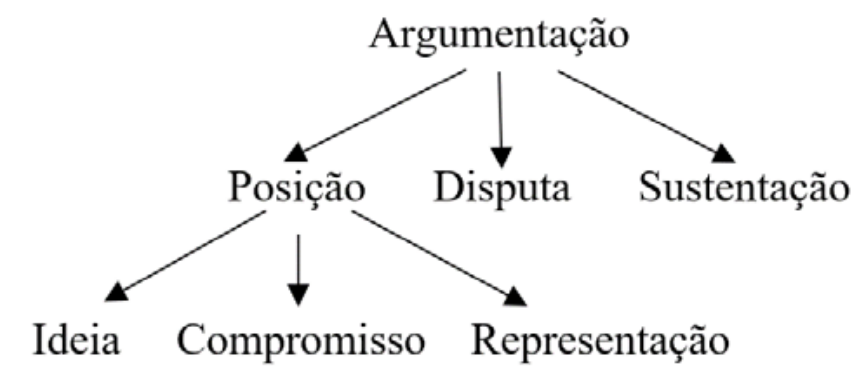

Gryner (2000) complementa esse esquema da argumentação dividindo a etapa de sustentação em duas, fundamentadas em evidências: "a evidência formal - especificação - que apresenta aspectos particulares e/ou alternativos da posição e evidência empírica exemplificação - que ilustra a posição através de fatos concretos" (GRYNER, 2000, p. 99). As evidências são baseadas em acontecimentos públicos, sendo considerados, ao menos em sua essência, verdadeiros. A diferença, segundo a autora, está no ângulo em que o analisam e como os participantes o expõem à audiência.

Esse artigo se centrará na disputa pelo ponto de vista assumido pelos participantes no curso da interação, sustentada pelos seus argumentos que nem sempre são baseados só em fatos concretos. Ao invés de posição e contraposição, esse trabalho assume os termos apresentação do ponto de vista e contestação do ponto de vista (PACHECO, 2019). O termo posição, nesse artigo, é destinado às teorias do papel social e do posicionamento, conforme mencionado na seção anterior.

\section{Aspectos metodológicos}

Nosso método de análise é qualitativo e interpretativo, pois consideramos a ação social inerentemente significativa, isto é, os conceitos e as teorias emergem dos dados e são exemplificados neles, em um processo de inter-relação (ERICKSON, 1998). As transcrições dos dados foram realizadas a partir das contribuições da Análise da Conversa (SACKS; SCHEGLOFF; JEFFERSON, 1974) na fonte Courier New 09, conforme prática da área, cujas convenções encontram-se em anexo. 
Os dados são compostos por quatro edições do programa Roda Viva ${ }^{5}$, transmitido pela TV Cultura de São Paulo e também pela internet em formato on-line. As quatro edições apresentam os seguintes entrevistados:

1. O então Ministro da Educação Paulo Renato Souza, em janeiro de 2000;

2. O então Ministro da Saúde José Gomes Temporão, em julho de 2007;

3. O então Deputado Federal e ex-Ministro da Casa Civil José Dirceu, em novembro de 2010;

4. O candidato à presidência Jair Messias Bolsonaro, em julho de 2018.

A escolha dessas quatro edições se deve ao fato de possuírem entrevistados relevantes à política brasileira à época das entrevistas e abarcarem diferentes épocas do cenário político-social brasileiro: o período de governo do presidente Fernando Henrique Cardoso, os dois mandatos do presidente Lula, a eleição da presidente Dilma Rousseff e a última campanha eleitoral à Presidência do Brasil. Acreditamos que esse amplo período de tempo, assim como as mudanças políticas provenientes desse período, possibilita a colheita de temas e discussões diversificadas e relevantes para a análise que propomos aqui.

Cabe ainda ressaltar que as entrevistas elencadas nesse artigo integram os dados do Projeto de Pesquisa A construção/negociação de papéis e posições na fala-em-interação institucional, coordenado por mim e financiado pela Universidade Federal de Juiz de Fora (UFJF).

\section{Análise dos dados}

Os quatro entrevistados, alvo desta análise, têm em comum a política como norteadora de seus papéis sociais projetados na interação. Desses papéis sociais, alguns são reivindicados pelo entrevistado e outros são atribuídos pelos entrevistadores ao entrevistado, que os refuta ou legitima. Essa negociação de papéis perpassa a defesa pelo ponto de vista no curso da interação. Vejamos um exemplo, retirado da entrevista com o então Ministro da Educação, Paulo Renato Souza, em janeiro de 2000:

\footnotetext{
5 O programa Roda Viva se apresenta como um programa de entrevista, em formato de "roda", na qual o entrevistado se posiciona no centro, cercado pelos entrevistadores, selecionados entre jornalistas dos principais veículos da imprensa brasileira, bem como especialistas na área de atuação profissional do entrevistado. Todos os entrevistadores possuem carreiras profissionais vinculadas ao tema que será debatido. Por exemplo, se o assunto é o judiciário, os jornalistas e/ou especialistas convidados trabalham em algum meio de informação da área jurídica ou são formados na área.
} 


\section{Excerto (1)}

178 Brasilis ministro, o senhor se entusiasmou muito com a sua- com o projeto de obter continuidade redução de custos, eficiência na universidade etc. e:: vamos ((gesto com as mãos indicando aspas))

184 Brasilis a universidade, essa eu acho que é a linguagem que tem sido o tom do ministério [desde o início]

186 Brasilis ministro parece o ministro da [fazenda da educação, mas]

187 Ministro [não é ajustar,] não é? não senhor, não não [ não hhh ]

Ministro não. não. tudo bem, termina aí hhh caracterizado muito o ministério, (...) obviamente a universidade tem que ser eficiente, etc. mas falta um projeto, uma espécie de utopia educacional que permita que o ministro da educação seja o líder da mudança ao invés de ser aquele que impõe a mudança.
219
Monica =foi só uma brincadeira por causa do ajuste.

Ministro a:: [ e:: ]

[eu só] queria fazer a colocação de um telespectador aqui que fica perfeitamente cabível. é carlos verge, que pergunta "se o ministro fosse presidente da república- se o senhor fosse presidente da república convidaria um economista para o ministério da educação?" ((risos de todos)) 
220 Ministro tá bom. vamo lá $(0,2)$ sabe quanto aumentou o orçamento da universidade pública brasileira nos últimos qua- cinco anos? vinte e oito por cento, não é? isso não é ajuste. nós estamos agora a:: o que, o que aconteceu? as verbas hoje são dirigidas com mais critério (...) nós aumentamos a verba de custeio e investimento para a universidade de cerca de trezentos e trinta milhões pra: seiscentos milhões milhões por ano $(0,3)$ então=

Ministro eu diria que hoje é possível que ainda tenhamos alguma situação como essa $(0,3)$ mas existe muito o problema de gestão da universidade, não é? Porque tem universi- as contas de luz são astronômicas. de água também (...) é é importante destacar que na na universidade nós temos uma política de estimular a universidade a TER mais alunos ah que possam ser alunos de transferência, isso é parte:: isso é parte de ajuste? NÂO. isso é parte que a universidade tem que cumprir suas funções [a universidade é ]

Brasilis [é que nunca se es]cuta o ministro ou autoridades ministeriais falarem de melhores doutores. se fala em mais doutores ou se falar em eh:: melhores universidades $(0,3)$ quer dizer a linguagem toda do ministe- eu não quero repetir mas é uma linguagem $(0,3)$ vamos dizer eh:: de economista de fato. hhh não é porque é o ministro [da economia hhh ]

$$
\text { Ministro [não é de economista] }(0,3)
$$

quero dizer o seguinte: quando eu assumi o governo, a universidade pública brasileira tinha dentro de seus quadros de professores uma proporção de vinte e dois por cento de doutores apenas. hoje tem mais de trinta por cento $(0,2)$ isso é linguagem de economista? NÂO. é que eu gosto de ver com números. eu tenho a obrigação de apresentar núme- isso é ser economista ou é ser uma pessoa racional? (...)

Marcos por falar em quantidade agrada ao senhor a relação professor aluno numa escola privada, que tem cem alunos numa sala de aula. isso é produtividade? 
- | A atribuição/reivindicação do papel social na construção da defesa do ponto de vista

\begin{tabular}{|c|c|c|}
\hline 296 & Ministro & a relação em media $(0,3)$ é da ordem de vinte- vinte e poucos alunos [por \\
\hline 297 & & professor] \\
\hline 298 & Brasiis & [media não é ] é mais [mais:: ] \\
\hline 299 & Ministro & [é possí]vel ter cem alunos numa sala. nós não vamos TER em \\
\hline 300 & & todas as materias. ter mais do que cinquenta alunos numa sala, ou trinta ou \\
\hline 301 & & vinte depende- \\
\hline 302 & Brasilis & ministro, dependendo acho que vinte está muito bom. eu sou professor- \\
\hline 303 & & \\
\hline 304 & Ministro & eu também sou professor \\
\hline 305 & Brasilis & vinte alunos numa sala é uma tourada \\
\hline
\end{tabular}

No excerto acima, diversos papéis sociais são manifestados na interação: Reitor, Secretário da Educação de São Paulo, Ministro da Educação, Ministro da Fazenda da Educação, Ministro da Economia, economista e professor. Desses papéis, apenas os três primeiros - Reitor, Secretário da Educação de São Paulo e Ministro da Educação - são reivindicados pelo entrevistado, sem que haja contestação por parte dos entrevistadores, ou seja, são papéis sociais que ao serem trazidos à interação não causam nenhum efeito de disputa argumentativa.

Apesar dos papéis Ministro da Fazenda da Educação (I. 186) e Ministro da Economia (I. 272) 6 terem sido atribuídos ao entrevistado através do riso e da brincadeira, esses papéis são utilizados como sustentação do argumento de que Paulo Renato, como Ministro da Educação, se preocupa muito mais com números e questões orçamentárias do que com a qualidade da educação em si, em termos de "melhores doutores" (I. 268), "melhores universidades" (I. 269) e "eficiência na universidade" (I. 179-180). Esse ponto de vista alocado nas atribuições desses papéis é contestado pelo entrevistado que os refuta: na primeira vez através do riso também (I. 187-190) e na segunda através da não menção direta ao papel atribuído, em uma fala sobreposta refutando outro papel - o de economista - (I. 273).

O papel de economista possui uma característica diferenciada nesse excerto, pois é legitimado em um primeiro momento (I.213) e refutado em um segundo (I.273, I. 277-280). Essa mudança na aceitação desse papel atribuído é usada como estratégia de defesa do ponto de vista. Ao legitimá-lo, o entrevistado ratifica a sua capacidade à frente do Ministério: se fosse um economista como eu convidaria, inclusive manifestando outros papéis (I. 214-218) que valorizam sua carreira profissional e, com isso, contam a seu favor nessa disputa de argumentos.

6 Ainda que esses papéis não retratem um cargo ministerial de fato, optamos aqui por considerá-los como atribuição de papel social, uma vez que há implícita nesse posicionamento uma categoria de grupo, como aponta Weizman (2006). 
Já no segundo momento, refutar a atribuição desse papel é imprescindível à defesa do ponto de vista de que o Ministro da Educação preza pela qualidade do ensino e de suas instituições e não pelos números e dados financeiros. Sendo assim, o entrevistado legitima e refuta o mesmo papel na sequência da interação em prol da defesa de seu ponto de vista, o que evidencia que o papel social é tornado relevante, de acordo com o interesse argumentativo do participante. A mesma situação se nota na reivindicação do papel de professor: tanto o entrevistador (I.302-302) quanto o entrevistado (I.304) reivindicam esse papel como evidência (GRYNER, 2000) de sustentação do ponto de vista.

A atribuição de posições, alocadas em papéis sociais também são usadas nos dados como defesa argumentativa. Veja o exemplo abaixo, entressacado da entrevista com Jair Bolsonaro:

Excerto (2)

30 Ricardo mas o senhor defende muito a volta né da: dos militares e vai cercar de

31 Lessa militares o seu governo hh mas o senhor parece num ter se dado muito bem

32 na vida militar (.)né? o senhor foi- saiu- foi expulso talvez do exército [e::]

33

Bolsonaro

[hhh]

35 Ricardo

depois é o: stm reformou e o senhor foi aposentado como capitão. então o

36 Lessa senhor defende a disciplina mas $(0,2)$ não era muito adaptado a disciplina= =tudo bem vamos lá é até bom porque no começo né falaram que: isso teria acontecido comigo. eu respondi $(0,2)$ uma transgressão disciplinar peguei quinze de retenção .hh e depois eu fui acusado por uma jornalista uma jornalista de ter um plano de botar bombas na vila militar. hh o superior tribunal militar arquivou o processo eu não fui expulso. quando eu me elegi vereador como diz a própria constituição por ocasião da data da da minha diplomação eu passei pra reserva. então eu sou um capitão da reserva do exército brasileiro. agora dei minhas caneladas sim agora nunca ofendi um superior na minha vida

É possível notar acima que o posicionamento indisciplinado atribuído ao entrevistado, alocado em seu papel social de militar, é refutado por ele, uma vez que nunca ofendi um superior na minha vida (I. 47), apesar de ter dado caneladas sim (I.46). No entanto, ao mencionar que ficou quinze dias retido devido a uma transgressão disciplinar (I.40), Bolsonaro acaba se posicionando como indisciplinado, legitimando a posição atribuída no papel de militar. 
- A atribuição/reivindicação do papel social na construção da defesa do ponto de vista

Cabe ressaltar que essa retenção de quinze dias se refere à punição que Bolsonaro obteve, enquanto militar, ao escrever à revista Veja em 1986 reivindicando aumento de salário ${ }^{7}$. Dessa forma, parece que o entrevistado não teve a clara noção desse autoposicionamento ao trazer essa informação para o discurso. Fica claro que, para ele, reivindicar aumento de salário não é uma indisciplina, o que ratificaria o refutar dessa posição atribuída.

A troca do papel social como sustentação do ponto de vista na disputa interacional é usada como estratégia argumentativa em diversos trechos das diferentes edições em análise. Na discussão sobre a descriminalização do aborto, por exemplo, o então Ministro da Saúde José Gomes Temporão apresenta, ao longo da entrevista, o seu ponto de vista de que essa questão deveria ser discutida em sociedade. O excerto a seguir é representativo do que discutimos aqui:

Excerto (3)

166 Reinaldo ministro. eu sou contra a ampliação do direito ao aborto,

(...)

178 se eu der de cara com um ninho de tartarugas e resolver fazer um omelete, eu

179 não faria isso por nojo e porque eu acho que

180 não é pra comer tartaruga.

181 mas eu seria preso, crime inafiançável, crime ambiental.

184 o senhor não a acha que os fetos brasileiros têm direito a pelo menos a mesma

$185 \quad$ lei que tem as tartarugas?

186 Ministro eu acho que as mulheres brasileiras que estão vivas merecem o direito à vida=

187

188 Reinaldo =e os fetos não?

189 Ministro eu defendo a vida. eu tenho quatro filhos.

190 sou de formação católica. sempre defendi e sempre vou continuar

191 defendendo $(0,2)$ eu não posso fechar os olhos para a realidade que eu expus

192 aqui. mulheres estão morrendo

Note que a primeira resposta do entrevistado, entre as linhas 186 e 187, é dada a partir do seu papel de Ministro atribuído pelo entrevistador (I.166), sem ser refutado por ele. Apesar da resposta ser evasiva à pergunta, ela é dada a partir do papel posicionado. Quando o entrevistador insiste na pergunta (I.188), o Ministro responde a partir de outros papéis - pai e católico - para sustentar o argumento de que como pai, católico ou Ministro, o entrevistado defende a vida, que é seu ponto de vista apresentado.

7 Conferir reportagem da revista Veja: https://veja.abril.com.br/blog/reveja/o-artigo-em-veja-e-a-prisao-debolsonaro-nos-anos-1980/ 
Outra característica interessante dessa manifestação do papel social na disputa argumentativa é a atribuição inferencial de papel, quer dizer, o entrevistador não cita diretamente o papel social em que posiciona o entrevistado. Ele o faz através de outras estruturas que sustentadas pelo discurso atribuem o papel desejado. Na entrevista com o então ex-Ministro José Dirceu, temos um exemplo dessa característica:

Excerto (4)

97 Augusto quando o presidente Fernando Henrique foi reeleito.

$98 \quad$ vocês pediram a queda [do presidente ( )]

99 Dirceu [NÂO. eu não pedi não] eu fui contra=

100 Augusto =você não gritou nenhuma [vez fora fh?]

101 Dirceu [NãO. JAMAIS ]eu- e o Fernando Henrique é testemunha disso. eu

102 falei pro lula(0,3)eu vou pra casa e entrego o cargo de [presidente do pt]

103

104 Augusto [então, mas:: ]

105 Dirceu fui contra. o pt derrotou isso, o pt derrotou isso. em noventa e 106 nove eu falei- falei pro lula você vai perder a eleição de novo=

107

108 Augusto =mas então [ Dirceu ]

109 Dirceu [em noventa] e três o pt aprovou fora itamar, itamar igual a collor, eu disse 110 a ele o senhor acabou de perder a eleição de presidente da república

111

Ao proferir vocês pediram a queda do presidente (I.98), no primeiro turno do excerto acima, o entrevistador Augusto Nunes posiciona o entrevistado em possíveis papéis associados ao Partido dos Trabalhadores (PT), cuja associação com José Dirceu é publicamente conhecida. Dentre esses papéis, podemos inferir todos os atribuídos e reivindicados por Dirceu ao longo da entrevista ${ }^{8}$, como Presidente do PT, membro do PT, Deputado Federal, Deputado Estadual e Ministro. Dirceu reconhece essa atribuição posicionada no vocês e responde a partir do papel reivindicado de Presidente do PT. Tanto para o entrevistador quanto para o entrevistado, é claro a que papel está atrelado o ponto de vista em discussão no curso da interação. Dirceu refuta o argumento, sustentando-a no turno o fernando henrique é testemunha. eu falei pro lula $(0,3)$ eu vou pra casa e entrego o cargo de [presidente do pt] (I.101-103), reivindicando, dentro dos papéis possíveis inferidos na atribuição, o papel de presidente do PT.

8 Conferir quadros no fim da análise de dados. 
- A atribuição/reivindicação do papel social na construção da defesa do ponto de vista

Essa estratégia de inferência de papéis sociais também pode ser utilizada na reivindicação de papéis, como se nota no excerto abaixo, entressacado da entrevista com Jair Bolsonaro:

\section{Excerto (5)}

180 Thaís eu queria só lembrar que apesar das suas negativas hoje mesmo o jornal suíço tribune

181 de jenève disse que o senhor, chamou o senhor de homofóbico, misógino e racista

187 Bolsonaro olha só. primeiro. se eu sou racista eu tinha que tá preso. eu não tenho imunidade se eu ofender um afro descendente agora e impedí-lo de entrar em um elevador tá. Isso é crime de racismo tem que ser preso.

190

191 Bernardo O senhor já foi [indiciado criminalmente]por isso

192 Bolsonaro [ são calú::nias ] calúnias isso

ai nada mais além disso calúnias como a questão de homofóbico. não. $(0,2)$ você não sabe e nem eu sei se você é ou também aqui também não sei não interessa para nós. O que não pode é o pai chegar em casa e encontrar o joãozinho de seis anos de idade brincando de boneca < por influência da escola $>\uparrow$ ah misógino.

201 Thais essa é a imagem que o jornal suíço tem do senhor

202 Bolsonaro mas a imprensa quase toda de esquerda no mundo. o trump sofreu muito com isso 203 são os fake News tá

A entrevistadora Thais Oyama apresenta uma evidência empírica que atribui três posicionamentos a Bolsonaro: homofóbico, misógino e racista (I. 182). No entanto, sua pergunta não se atém a esses posicionamentos; eles apenas a sustentam. O entrevistado, na sequência de seus turnos, refuta esses posicionamentos, apresentando argumentos alocados em papéis não mencionados, porém claramente inferidos: ao afirmar eu não tenho imunidade (I.188) e a minha briga é contra o material escolar (I.194), Bolsonaro sustenta seu ponto de vista contrário a esses posicionamentos através de seu papel de deputado federal e até de cidadão, uma vez que a imunidade poderia estar atrelada ao seu papel de cidadão comum, sem foro privilegiado. 
É interessante notar que essas atribuições/reivindicações inferenciais do papel social, retratadas nos exemplos acima, são entendidas pelos participantes envolvidos através do próprio discurso, o que evidencia que nem sempre se faz necessário mencionar o papel social nas negociações interacionais para alcançar o objetivo da meta argumentativa de defesa na disputa.

A seguir, concluímos a análise apresentando dois quadros sinópticos dos dados. No primeiro consta o papel social reivindicado pelos entrevistados em cada edição. O segundo retrata o papel social atribuído pelos entrevistadores, sendo refutado ou legitimado por cada entrevistado.

\begin{tabular}{|c|c|}
\hline Entrevistado & Papel social reivindicado \\
\hline Paulo Renato Souza & $\begin{array}{r}\text { Ministro da Educação / Economista / Reitor / Secretário da Educação } \\
\text { / Professor / Doutor / Candidato ao Senado }\end{array}$ \\
\hline José Gomes Temporão & $\begin{array}{c}\text { Ministro da Saúde / Médico Sanitarista / Pai / Católico / Cidadão / } \\
\text { Professor da Fiocruz }\end{array}$ \\
\hline José Dirceu & $\begin{array}{c}\text { Ministro da Casa Civil / Ex-Ministro da casa Civil / Deputado Estadual } \\
\text { / Deputado Federal / Presidente do PT / Presidente de Centro } \\
\text { Acadêmico / Dirigente do PT / Escritor / Cidadão / Consultor / } \\
\text { Advogado }\end{array}$ \\
\hline Jair Bolsonaro & $\begin{array}{c}\text { Deputado Federal / Vereador / Presidenciável / Pai / Genro / Militar } \\
\text { / Cidadão / Parlamentar / Religioso / Capitão }\end{array}$ \\
\hline
\end{tabular}

\begin{tabular}{|c|c|c|c|}
\hline Entrevistado & Papel social atribuído & Refutado & Legitimado \\
\hline \multirow{4}{*}{$\begin{array}{c}\text { Paulo Renato } \\
\text { Souza }\end{array}$} & Ministro da Educação & & $\mathrm{X}$ \\
\cline { 2 - 4 } & Economista & $\mathrm{X}$ & $\mathrm{X}$ \\
\cline { 2 - 4 } & Presidenciável & $\mathrm{X}$ & $\mathrm{X}$ \\
\cline { 2 - 4 } & Político & $\mathrm{X}$ & \\
\cline { 2 - 4 } & Ministro da Economia & $\mathrm{X}$ & $\mathrm{X}$ \\
\hline \multirow{3}{*}{$\begin{array}{c}\text { José Gomes } \\
\text { Temporão }\end{array}$} & Ministro da Saúde & & $\mathrm{X}$ \\
\cline { 2 - 4 } & Médico Sanitarista & $\mathrm{X}$ \\
\cline { 2 - 4 } & Ministro de Estado & & $\mathrm{X}$ \\
\cline { 2 - 4 } & Dirigente & & \\
\cline { 2 - 4 } & Técnico do Ministério da Saúde & & \\
\hline
\end{tabular}


- | A atribuição/reivindicação do papel social na construção da defesa do ponto de vista

\begin{tabular}{|c|c|c|c|}
\hline \multirow{6}{*}{ José Dirceu } & Membro do PT & & $x$ \\
\hline & Ex-Ministro da casa Civil & & $x$ \\
\hline & Eleitor & ---- & ---- \\
\hline & Consultor & & $x$ \\
\hline & Lobista & $X$ & \\
\hline & Ministro da Casa Civil & & $\mathrm{X}$ \\
\hline \multirow{8}{*}{ Jair Bolsonaro } & Candidato & & $x$ \\
\hline & Político & & $x$ \\
\hline & Parlamentar & & $x$ \\
\hline & Deputado Federal & & $x$ \\
\hline & Ex-Capitão & & $x$ \\
\hline & Capitão & & $x$ \\
\hline & Cristão & & $x$ \\
\hline & Militar & & $x$ \\
\hline
\end{tabular}

Um resultado curioso que apontam os quadros acima é o fato de a maioria dos papéis atribuídos ser legitimada pelo entrevistado. Fato que não impede as situações de disputa ocorridas em torno dessas atribuições legitimadas, como por exemplo vimos na atribuição do papel de militar a Bolsonaro e de Ministro da Saúde a Temporão, na discussão sobre a descriminalização do aborto. Todos os papéis refutados participaram das situações de disputa encontradas nos dados.

Um ponto interessante na listagem dos papéis atribuídos, que não se observa nos papéis reivindicados, é que todos giram em torno da ocupação profissional/institucional do entrevistado, inclusive o eleitor, atribuído a Dirceu como "o maior eleitor de Dilma", sendo ele dirigente do PT, e cristão, atribuído a Bolsonaro, por defender como candidato à presidência a tortura e o armamento da população.

\section{Considerações finais}

Esse artigo partiu do pressuposto de que os papéis sociais do indivíduo manifestados no encontro podem tornar-se fontes de conflito em situações de disputa na interação. Nesse sentido, ao analisarmos como a atribuição e a reivindicação do papel social são negociadas pelos interagentes nos dados de análise, percebemos que essa negociação é usada como estratégia argumentativa de defesa de ponto de vista. 
Tanto os quadros sinópticos apresentados na seção anterior quanto os excertos analisados alcançam o objetivo proposto a esse trabalho e evidenciam que ao legitimar ou refutar os papéis sociais atribuídos, assim como reivindicá-los, os participantes negociam seus pontos de vista na interação. Essa defesa do ponto de vista é perpassada por estratégias argumentativas, como as trocas de papel entre os turnos de resposta do entrevistado, a mudança interacional na aceitação de papéis e posições e as inferências nas atribuições e reivindicações dos papéis. Todas essas estratégias corroboram ao pressuposto teórico de que a expectativa interacional da entrevista-debate, que caracteriza o programa Roda Viva (PACHECO, 2019), é de fato a disputa argumentativa na defesa dos pontos de vista em busca pelos melhores argumentos de convencimento da opinião pública.

\section{Referências}

EMMERTSEN, S. Interviewers' challenging questions in British debate interviews. Journal of Pragmatics, n. 39, p. 570-591, 2007.

ERICKSON, F. Qualitative Research Methods of Science Education. In: FRASER, B.; TOBIN, K. International Handbook of Science Education. Springer, 1998. p. 1155-1173.

GOFFMAN, E. A Representação do Eu na Vida Cotidiana. 13. ed. Petrópolis: Vozes, 2005.

GRYNER, H. A sequência argumentativa: estrutura e funções. Veredas - Revista de Estudos Linguísticos, Juiz de Fora, v. 4, n. 2, p. 97-112, jul./dez. 2000.

LANGENHOVE, L. V.; HARRÉ, R. Introducing positioning theory. In: HARRÉ, R.; LANGENHOVE, L. V. Positioning Theory: moral contexts of intentional action. Oxford: Blackwell Publishers, 1999. p. 14-31.

PACHECO, R. A dinamicidade de papéis e posições em uma entrevista-debate. Revista Recorte, v. 15, n. 2, p. 1-20, 2018 a.

PACHECO, R. A conceptualização de papel: uma revisão teórica. Estudos da Língua(gem), v. 16, n. 2, p. 69-80, 2018b.

PACHECO, R. Entrevista-debate: características de uma atividade interacional híbrida. Veredas - Revista de Estudos Linguísticos, v. 2, n. 23, p. 33-52, 2019. 
- | A atribuição/reivindicação do papel social na construção da defesa do ponto de vista

RODA VIVA. Produção: Fundação Padre Anchieta. Centro Paulista de Rádio e Tv Educativas. Disponível em: http://tvcultura.cmais.com.br/rodaviva. Acesso em: 20 mar. 2018.

SACKS, H.; SCHEGLOFF, E.; JEFFERSON, G. A Simplest Systematic for the Organization of Turn Taking for Conversation. Language, v. 50, n. 4, p. 696-735, 1974.

SARANGI, S. Reconfiguring Self/Identity/Status/Role: The Case of Professional Role Performance in Healthcare Encounters. Journal of Applied Linguistics and Professional Practice, p. 75-95, 2010.

SARANGI, S. Role hybridity in professional practice. In: SARANGI, S.; POLESE, V.; CALIENDO, G. (ed.). Genre(s) on the Move: Hybridisation and Discourse Change in Specialised Communication. Napoli: Edizioni Scientifiche Italiane (ESI), 2011.

SCHIFFRIN, D. Dircourse Markers. Cambridge: Cambridge University Press, 1987.

VAN EEMEREN, F.; GROOTENDORST, R.; JOHNSON, R. Fundamentals of argumentation theory: a handbook of historical backgrounds an contemporary developments. Mahwah, NJ: Lawrence Erlbaum, 1997.

VIEIRA, A. A formulação de perguntas em entrevistas televisivas. In: V Congresso de Ciências Humanas, Letras e Artes, Ouro Preto, 2002.

WEIZMAN, E. Roles and identities in news interviews: The Israeli context. Journal of Pragmatics, v. 38, p. 154-179, 2006.

WEIZMAN, E. Positioning in media dialogue: negotiating roles in the news interview. Série Dialogue Studies. Amsterdam - Philadelphia. John Benjamins Publishing, 2008. 


\section{Convenções de Transcrição} pausa em décimos de segundo, medida relativamente ao ritmo prosódico do segmento no qual se encontra inserida.

entonação descendente ou final de elocução.

? entonação ascendente.

entonação de continuidade.

parada súbita.

$=\quad$ elocuções contíguas, enunciadas sem pausa entre elas.

palavra ênfase (parte da sílaba e/ou palavra).

MAIÚSCULA ênfase mais forte ou fala em voz alta.

! tom animado, não necessariamente exclamativo.

>palavra $\quad$ fala mais rápida.

$<$ palavra $\quad$ fala mais lenta.

: ou :: $\quad$ alongamentos.

início de sobreposição de falas.

final de sobreposição de falas.

colchetes duplos no início do turno simultâneo.

$\uparrow$ subida de entonação (mudança de entonação).

$\downarrow \quad$ descida de entonação (mudança de entonação).

hh aspiração (em parênteses quando no meio de palavra).

.hh inspiração (em parênteses quando no meio de palavra).

hhh riso (em parênteses quando no meio de palavra). 
- A atribuição/reivindicação do papel social na construção da defesa do ponto de vista

COMO CITAR ESTE ARTIGO: PACHECO, Roberta Fernandes. A atribuição/ reivindicação do papel social na construção da defesa do ponto de vista. Revista do GEL, v. 17, n. 1, p. 214-233, 2020. Disponível em: https://revistas.gel.org.br/rg

DOI: http://dx.doi.org/10.21165/gel.v17i1.2830

Submetido em: 13/04/2020 | Aceito em: 04/06/2020. 